\title{
Microstructural and Mechanical Characterization of Dissimilar Metal Welding of Inconel 625 and AISI 316L
}

\author{
Fatih Dokme ${ }^{1,2, *}$, Mustafa Kemal Kulekci ${ }^{2}$ and Ugur Esme ${ }^{2}$ \\ 1 Sisecam Chemicals Group Soda Sanayii A.S. Kromsan Chromium Chemicals Plant, 33003 Mersin, Turkey \\ 2 Tarsus University Faculty of Technology, 33400 Mersin, Turkey; mkkulekci@yahoo.com (M.K.K.); \\ uguresme@gmail.com (U.E.) \\ * Correspondence: fdokme@gmail.com; Tel.: +90-324-241-6810
}

Received: 4 September 2018; Accepted: 2 October 2018; Published: 4 October 2018

\begin{abstract}
This study investigated the microstructure of the dissimilar metal welding of Inconel 625 and AISI 316L using Continuous Current Gas Tungsten Arc Welding (CCGTAW) and Pulsed Current Gas Tungsten Arc Welding (PCGTAW) processes with ERNiCr-3, TIG 316L and twisted (ERNiCr-3 and TIG 316L) fillers. Microstructure examinations were carried out using an optical microscope and Scanning Electron Microscopy (SEM)/Energy Dispersive X-Ray (EDAX). The results of the study showed the existence of a partially melted zone (PMZ) on the AISI 316L side. Weld zone (WZ) analysis showed the existence of a multi-directional grain growth on the $316 \mathrm{~L}$ side in all specimens, although less growth was found on the Inconel 625 side. Grain growth almost disappeared using PCGTAW with twisted fillers. SEM/EDAX investigations indicated that secondary deleterious secondary phases were tiny and white in five experiments. However, a meager amount of precipitates occurred in PCGTA welding with twisted fillers. Moreover, these were particularly innocent precipitates, represented by black dots in images, whereas other tiny white secondary phases are known to be brittle. As a result, PCGTA welding with twisted fillers exhibited the best metallurgical properties.
\end{abstract}

Keywords: dissimilar metal welding; Inconel 625; AISI 316L; microstructure; filler metals

\section{Introduction}

Inconel 625 is a nickel-based super alloy, which has good corrosion resistance properties at cryogenic as well as very high temperatures. Thus, it is the preferred material in many heavy industries. It is used in the reactor-core of nuclear power plants, boilers, piping, exhaust systems of racing cars, impellers of chemical vessels, power plant turbine blades, aerospace engine components, etc. [1-3]. It is often used as dissimilar joints, with several metals in field applications. For example, bimetallic joints of Inconel 625 and AISI $304 \mathrm{~L}$ are used in high temperature media in thermal power and nuclear power plants to cryogenic applications [4]. Bimetallic joints of Inconel 625 and duplex stainless steel pipes are used in sub-sea manifolds [5]. Bimetallic combinations of Inconel 625 and austenitic stainless steels were used by NASA for manufacturing of sub-scale boilers [6]. The bimetallic joints of Inconel 625 and austenitic stainless steel AISI $316 \mathrm{~L}$ are used in the chemical process at very high temperatures, especially the chromic acid calcining process, which contains a diluted acidic environment. Therefore, many researchers have studied it during last decade [7-11]. One of the main reasons is that it reduces cost of materials, and the other is that it improves design as a result of operating environment requirements [12]. Different metals have different chemical and physical properties; hence, the dissimilar metal welding process has some disadvantages. A weld pool consists of a molten metal mixture, which has unknown 
chemical and mechanical properties $[13,14]$. Thus, some specific parameters, such as proper filler metal and current type selection, could minimize weld defects.

Gas Tungsten Arc Welding (GTAW) is one the preferred dissimilar welding technique in the manufacturing industry due to its high development, ease of use, low investment value and low operating cost. The main disadvantage of GTAW is that the welding of thick parts requires a multi-pass, which causes a higher heat input. This causes a Laves phase formation as a result of the segregation of $\mathrm{Nb}$ and Mo at a high temperature. This leads to a change in the microstructure and mechanical properties of both the heat affected zone (HAZ) and weld zone, leading to a decreased corrosion resistance [15].

Because of the content of $\mathrm{Nb}$ and Mo elements, Inconel 625 exhibits a precipitation disposition in welding treatment. The solidification of Inconel 625 starts at nearly $1368^{\circ} \mathrm{C}$. During fusion weld overlay solidification, $\mathrm{NbC}$ carbides ( $\mathrm{LE} \rightarrow \gamma+\mathrm{NbC}$ ) and austenite forms occur at $1250{ }^{\circ} \mathrm{C}$, and an austenite and brittle intermetallic Laves phase ( $\mathrm{LE} \rightarrow \gamma+$ Laves phase) occurs at $1150^{\circ} \mathrm{C}$. If the alloy has a high Si and low C content, an additional carbide (M6C) could occur during solidification [16].

Ramkumar et al. [10] studied the corrosion behavior of the similar and dissimilar TIG welding of Inconel 718 and SS 316L. Both similar weldments of Inconel 718 and SS 316L possessed a lower hardness value than that of dissimilar weldments. A higher hardness occurred as a result of the brittle phases of $\mathrm{Cr}$ and Ni precipitation in HAZ. Corrosion tests showed that the maximum weight loss was found in dissimilar weldments, which backed up the thesis that carbides decrease corrosion resistance. In some studies, various improvements were recommended for minimizing micro-segregations and precipitates in a liquid nitrogen aided cooling system for GTAW [17], double shot laser shock peening on the fusion zone [18], and a post weld heat treatment (PWHT) [16,19]. PWTH reduces residual stresses, although it causes increasing precipitations [20] in some cases.

One of the major parameters for dissimilar welding is the selection of appropriate filler metals for both base metals. Prabu et al. [21] studied the effects of two filler materials, ErNiCrMo-4 and ERNiCrCoMo-1, on the dissimilar welding of Inconel 625 and AISI 904L using GTAW. Researchers found that the segregated zone is wider and more visible in ERNiCrCoMo-1 welding compared with ERNiCrMo-4 welding, because of the migration of C. Ni-based filler metal and AISI $904 \mathrm{~L}$ have different chemical compositions, and a wider unmixed zone occurred on the AISI $904 \mathrm{~L}$ side rather than on the Inconel 625 side. This is evidence of the importance of the similarity between base and filler metals in the welding process. Moosavy et al. [22] investigated the microstructural evolutions of the dissimilar welding of AISI 310 and Inconel 657 using four types of filler metals: Inconel 82, Inconel A, Inconel 617 and type 310 SS. Thus, the presence of a high Mo content of Inconel 617 filler generated brittle phases. Likewise, $310 \mathrm{SS}$ led to continuous precipitates. Inconel 82 generated $\mathrm{NbC}$ precipitates, whereas Inconel A did not show the formation of $\mathrm{NbC}$ in the interdentric region. PWHT ensured the removal of the unmixed zone of Inconel 657 on the base metal side. Mortezaie and Shamanian [9] studied the dissimilar welding of Inconel 718 and AISI 310S using GTAW with three different filler metals. According to their results, Inconel 82 exhibited the best corrosion resistance and highest energy impact in a V-Charpy test. Ramkumar et al. [23] researched the influence of filler metal and welding techniques on the dissimilar welding of Inconel 718 and AISI 316L. The authors used two filler materials, ER2553 and ERNiCu-7, and two welding techniques, Continuous Current Gas Tungsten Arc Welding (CCGTAW) and Pulse Current Gas Tungsten Arc Welding (PCGTAW). They controlled the precipitations through PCGTAW. Furthermore, the $\mathrm{Nb}$ free ErNiCu-7 filler did not cause precipitations. Hejripour and Aidun [24] conjoined Inconel 718 and AISI 410 by GTAW. Researchers selected the twisted filler metals of 718-410 and 82-410. Secondary phase formations formed a higher volume in the 718-410 weld zone than in the 82-410 weld zone because of the higher $\mathrm{Nb}$ content.

Kumar et al. [25] investigated metallurgical and mechanical properties of bimetallic joints of Inconel 625 and AISI 316L materials. Researchers used CCGTA and PCGTA welding processes employing ERNiCr-3 and ER2209 filler metals. Microstructural investigations showed that secondary phases were occurred at the HAZ of Inconel 625 employing ERNiCr-3 filler metal. 
However, PCGTA welding minimized secondary phases formation. Tensile tests present all fractures occurred at the parent metal of AISI 316L. And both welding techniques employing ERNiCr-3 exhibited better mechanical properties. Researchers recommend PCGTA welding employing ERNiCr-3 for bimetallic joints of Inconel 625 and AISI 316L. In another study focused on dissimilar welding of Inconel 625 and AISI 316 L, Kournadi and Haghighi [26] investigated the effects of different welding methods on metallurgical and mechanical properties. Authors used shield metal arc welding (SMAW) and GTA welding employing ERNiCrMo-3 and TIG 316L filler metals and an electrode NiCrMo-3. Results showed that SMA welding reduced metallurgical and mechanical properties. GTA welding employing ERNiCrMo-3 exhibited the best properties for welding Inconel 625 and AISI 316L.

There are several welding methods, such as laser beam (LB), electron beam (EB), friction stir, explosion welding (EW), etc., for joining various dissimilar metals. Xie et al. [27] investigated interface characteristics of explosive welded and hot rolled TA1/X65 bimetallic plate. In the vortex zone brittle intermetallic compounds and cracks were detected. Topolski et al. [28] studied the properties of Ti6Al4V/Inconel 625 Bimetal obtained by EW. Results showed that chemical composition was clearly changed in the fusion line and elemental transfer was obtained between the metals. The main disadvantage of EW is its use of thin sheets. Mohammed et al. [29] studied the fiber laser welding of duplex stainless steel 2205 and austenitic stainless steel 304. From the SEM results, formation of micro-voids confirmed the ductile mode of fracture. Small HAZ obtained between metals and rapid solidification in the fusion zone improved the mechanical properties of the weldments. Shakil et al. [30] investigated electron beam welding of dissimilar Inconel 625 and AISI 304L. Columnar and cellular dendritic microstructures were observed in the fusion zone. Ni and Fe elements transferred from Inconel 625 to FZ and from FZ to AISI 304L. These technological welding types provide some advantages on metallurgical and mechanical properties of weldments. However, there are similarly some problems, such as undesirable elemental transfers, presence of brittle structures, etc. On the other hand, they have weaknesses such as thickness limits, as well as investment and operating costs. Therefore, GTA welding is commonly used with cheap costs and wider thickness limits.

Although bimetallic joints of Inconel 625 and AISI 316L metals used several applications, limited studies focused on the dissimilar metal welding of Inconel 625 and AISI 316L. Furthermore, studies that focused on the dissimilar metal welding of Inconel and stainless steel experimented with thin plates in general. In this investigation, $20 \mathrm{~mm}$ thickness Inconel 625 and AISI 316L, conjoined with CCGTA and PCGTA welding processes with ERNiCr-3, TIG 316L and twisted of both filler metals, was studied. TIG 316L is a Nb free filler, which is expected to prevent the Laves phase. Metallurgical characterizations were carried out using Optical Microscopy (OM) and Scanning Electron Microscopy (SEM), and compositional analysis was carried out using Energy Dispersive Spectroscopy (EDS). The results of microstructural tests are presented in corresponding sections.

\section{Materials and Methods}

The chemical composition of the as-received solution of annealed Inconel 625 and AISI 316L base metals and filler metals are given in Table 1 . Base metals were machined to rectangular samples with the following dimensions: $200 \mathrm{~mm} \times 60 \mathrm{~mm} \times 20 \mathrm{~mm}$. Standard double V-Butt configurations (with a root face thickness of $1 \mathrm{~mm}$, a $2 \mathrm{~mm}$ gap, and with a $60^{\circ}$ angle) were employed for the samples. Two filler wires were selected: ERNiCr-3 and TIG316L (thickness $3.2 \mathrm{~mm}$ ). However, both wires combined and created a third filler metal for welding. Three of the samples were welded using CCGTA welding, whereas the other three samples were welded using the PCGTA welding process.

Welding parameters are given in Table 2 . High purity argon gas $(99.9 \%)$ was used as a shielding gas at $15 \mathrm{~L}$ per minute. Samples were welded using the semi-automatic GTAW (automatic welding speed with manual filler feeding) setting of the Fronius Magicwave Synergic 2200 (Fronius International $\mathrm{GmbH}$, Wels/Austria) welding machine (shown in Figure 1) in continuous and pulsed current modes. After welding, samples were sliced to several coupons for mechanical and metallurgical tests. 


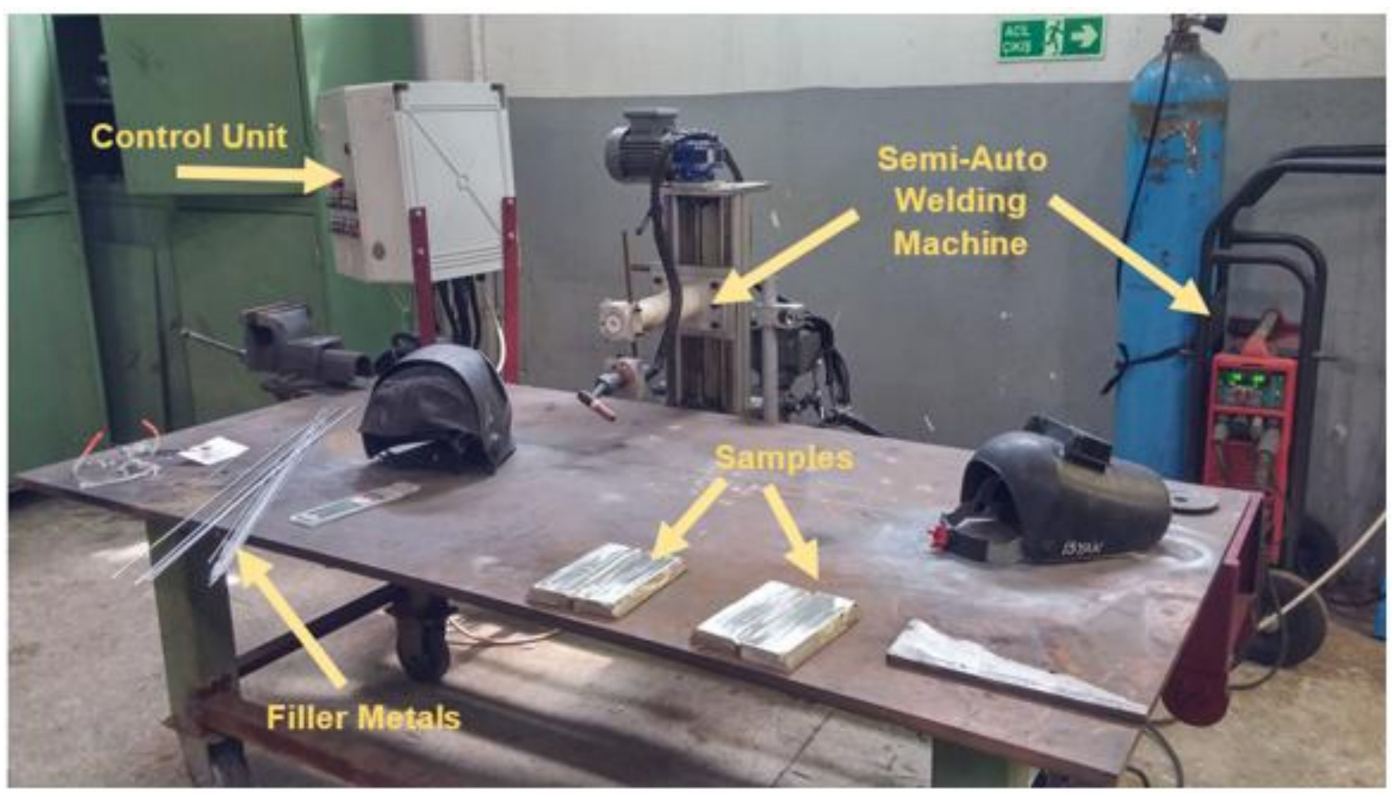

Figure 1. Semi-automatic Gas Tungsten Arc Welding (GTAW) setting.

Table 1. Chemical composition of the base and filler metals (wt \%).

\begin{tabular}{|c|c|c|c|c|c|c|c|c|c|c|}
\hline Base/Filler & C & $\mathrm{Cr}$ & Si & $\mathbf{N i}$ & $\mathbf{P}$ & Mn & $\mathrm{Nb}+\mathrm{Ta}$ & Mo & $\mathrm{Fe}$ & Other \\
\hline $\begin{array}{c}\text { Inconel } \\
625\end{array}$ & 0.04 & 22.12 & 0.15 & Rem. & 0.012 & 0.09 & 3.38 & 8.32 & 4.48 & $\begin{array}{c}\mathrm{Cu}-0.05 \\
\mathrm{Al}-0.11 \\
\mathrm{Ti}-0.21 \\
\mathrm{Co}-0.3\end{array}$ \\
\hline AISI 316L & 0.02 & 17.25 & 0.04 & 10.38 & 0.039 & 1.78 & - & 2.15 & Rem. & $S-0.004$ \\
\hline ERNiCr-3 & 0.04 & 20.0 & 0.09 & 73.00 & 0.003 & 2.8 & 2.4 & - & 1.5 & $\begin{array}{c}\mathrm{Ti}-0.40 \\
\mathrm{~S}-0.002 \\
\mathrm{Cu}-0.03 \\
\text { Other }<0.5\end{array}$ \\
\hline TIG316L & 0.02 & 18 & 0.45 & 12 & 0.04 & 1.70 & - & 2.3 & Rem. & $\begin{array}{c}\mathrm{Cu}-0.75 \\
\mathrm{~S}-0.03\end{array}$ \\
\hline
\end{tabular}


Table 2. Process parameters employed in Continuous Current Gas Tungsten Arc Welding (CCGTAW) and Pulse Current Gas Tungsten Arc Welding (PCGTAW).

\begin{tabular}{|c|c|c|c|c|c|c|c|c|}
\hline \multirow{2}{*}{ Welding } & \multirow{2}{*}{ Filler } & \multirow{2}{*}{ Pass } & \multicolumn{2}{|c|}{ Current (A) } & \multirow{2}{*}{ Voltage (V) } & \multirow{2}{*}{ Duty Cycle } & \multirow{2}{*}{$\begin{array}{l}\text { Frequency } \\
\quad(\mathrm{Hz})\end{array}$} & \multirow{2}{*}{$\begin{array}{l}\text { Welding Speed } \\
(\mathrm{mm} / \mathrm{s})\end{array}$} \\
\hline & & & Peak & Back & & & & \\
\hline \multirow{18}{*}{ CCGTAW } & \multirow{6}{*}{ ERNiCr3 } & Root 1 & 110 & - & 14 & - & - & 0.56 \\
\hline & & Pass 1 & 110 & - & 17 & - & - & 0.71 \\
\hline & & Cap 1 & 110 & - & 18 & - & - & 0.95 \\
\hline & & Root 2 & 110 & - & 15 & - & - & 0.65 \\
\hline & & Pass 2 & 110 & - & 17 & - & - & 0.82 \\
\hline & & Cap 2 & 110 & - & 20 & - & - & 1.09 \\
\hline & \multirow{6}{*}{ TIG 316L } & Root 1 & 110 & - & 15 & - & - & 0.62 \\
\hline & & Pass 1 & 110 & - & 17 & - & - & 0.79 \\
\hline & & Cap 1 & 110 & - & 19 & - & - & 1.02 \\
\hline & & Root 2 & 110 & - & 13 & - & - & 0.78 \\
\hline & & Pass 2 & 110 & - & 16 & - & - & 0.92 \\
\hline & & Cap 2 & 110 & - & 18 & - & - & 1.18 \\
\hline & \multirow{6}{*}{ TWISTED } & Root 1 & 120 & - & 16 & - & - & 0.81 \\
\hline & & Pass 1 & 120 & - & 19 & - & - & 1.02 \\
\hline & & Cap 1 & 120 & - & 20 & - & - & 1.15 \\
\hline & & Root 2 & 120 & - & 14 & - & - & 0.95 \\
\hline & & Pass 2 & 120 & - & 16 & - & - & 1.13 \\
\hline & & Cap 2 & 120 & - & 18 & - & - & 1.29 \\
\hline \multirow{18}{*}{ PCGTAW } & \multirow{6}{*}{ ERNiCr3 } & Root 1 & 170 & 100 & 12 & $50 \%$ & 6 & 0.56 \\
\hline & & Pass 1 & 170 & 100 & 15 & $50 \%$ & 6 & 0.71 \\
\hline & & Cap 1 & 170 & 100 & 16 & $50 \%$ & 6 & 0.95 \\
\hline & & Root 2 & 160 & 90 & 13 & $50 \%$ & 6 & 0.65 \\
\hline & & Pass 2 & 150 & 85 & 14 & $50 \%$ & 6 & 0.82 \\
\hline & & Cap 2 & 150 & 85 & 16 & $50 \%$ & 6 & 1.09 \\
\hline & \multirow{6}{*}{ TIG 316L } & Root 1 & 170 & 100 & 11 & $50 \%$ & 6 & 0.62 \\
\hline & & Pass 1 & 170 & 100 & 15 & $50 \%$ & 6 & 0.79 \\
\hline & & Cap 1 & 170 & 100 & 17 & $50 \%$ & 6 & 1.02 \\
\hline & & Root 2 & 160 & 90 & 10 & $50 \%$ & 6 & 0.78 \\
\hline & & Pass 2 & 150 & 85 & 14 & $50 \%$ & 6 & 0.92 \\
\hline & & Cap 2 & 140 & 80 & 16 & $50 \%$ & 6 & 1.18 \\
\hline & \multirow{6}{*}{ TWISTED } & Root 1 & 180 & 110 & 13 & $50 \%$ & 6 & 0.81 \\
\hline & & Pass 1 & 170 & 100 & 15 & $50 \%$ & 6 & 1.02 \\
\hline & & Cap 1 & 170 & 100 & 17 & $50 \%$ & 6 & 1.15 \\
\hline & & Root 2 & 170 & 100 & 12 & $50 \%$ & 6 & 0.95 \\
\hline & & Pass 2 & 160 & 90 & 14 & $50 \%$ & 6 & 1.13 \\
\hline & & Cap 2 & 150 & 85 & 15 & $50 \%$ & 6 & 1.29 \\
\hline
\end{tabular}

Each sample has been studied with respect to both parent metals, both heat affected zones (HAZ), and a weld zone in five sections. Specimens were polished using the sandpaper sheets of silicon carbide (SiC) with various grit sizes from 150 to 1000, then by a final mechanical polishing with $2 \mu \mathrm{m}$ polishing paste. To display the microstructures at the specified zones of weldments, a mixture of $10 \%$ oxalic acid was used for electrolytic etching, with a 6 DC supply for $20 \mathrm{~s}$ at room temperature. Optical investigations were carried out using Carl Zeiss brand Axio Imager M2M model optical microscope (Carl Zeiss, Cambridge, UK). The microstructural and element distribution analysis were carried out using Carl Zeiss brand Evo MA10 model Scanning Electron Microscope (SEM) (Carl Zeiss, Cambridge, UK) equipped with an Ametek brand Apollo X model Energy Dispersive Spectrometer (EDS) (Ametek, Mahwah, NJ, USA). Both point and line mapping analyses were implemented to reveal elemental displacements across weldments. 


\section{Results}

\subsection{Macrostructure of the Weldments}

The photographs of both the CCGTAW and PCGTAW dissimilar weldments of Inconel 625 and AISI 316L metals are shown in Figure 2. Weld seams are free of slags. The cross-section macrographs of the CCGTA and PCGTA welded samples are shown in Figure 3.
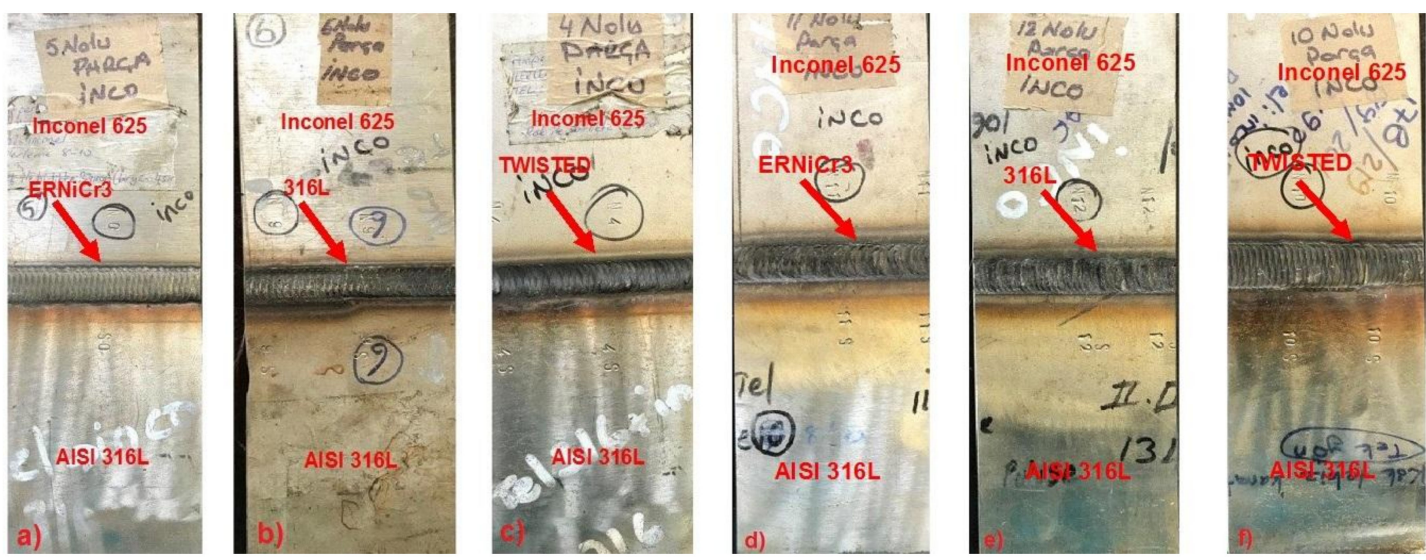

Figure 2. Photographs of the CCGTA (a-c) and PCGTA (d-f) weldments of Inconel 625 and AISI 316 L.
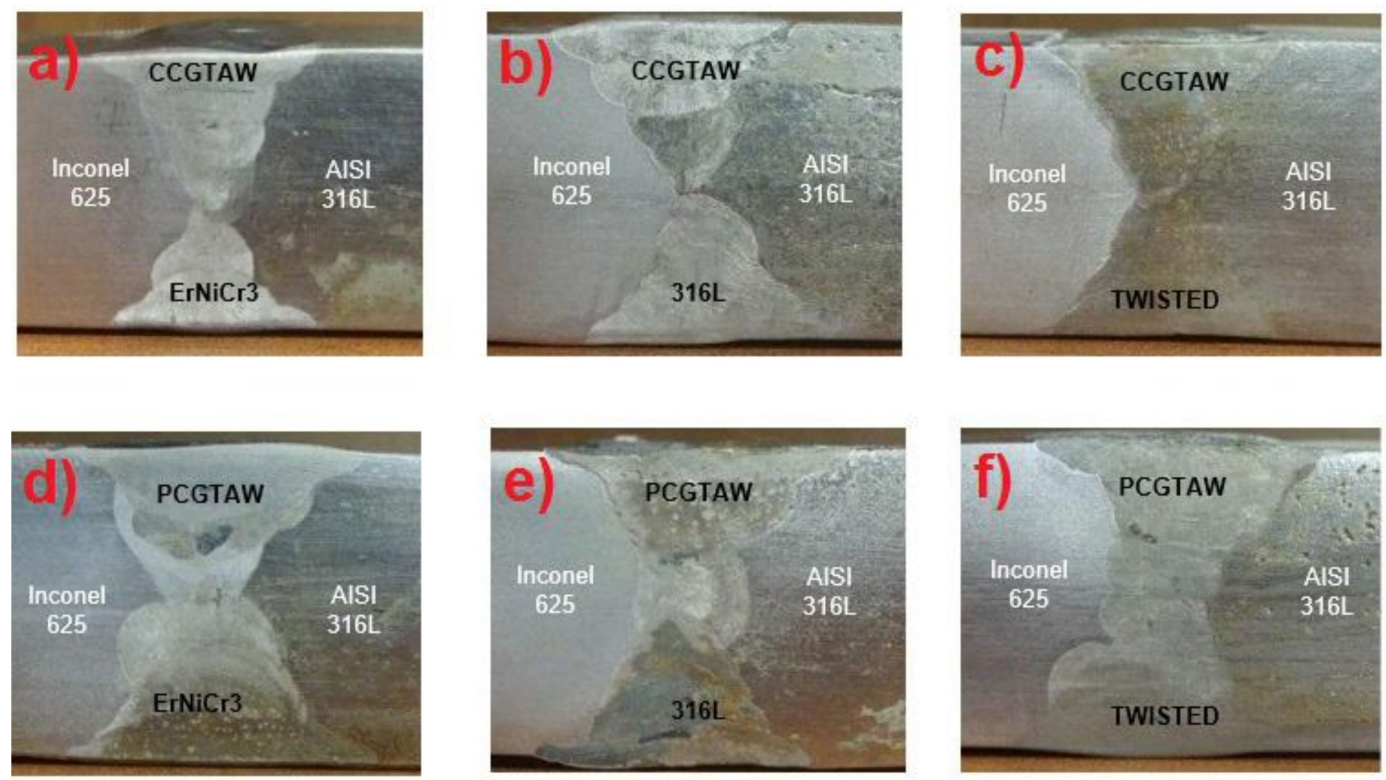

Figure 3. Cross-section macrographs of the CCGTA (a-c) and PCGTA (d-f) weldments of Inconel 625 and AISI 316 L.

According to visual testing (VT) and ultrasonic testing (UT), all experiments present full penetration without any lack, porosities, spatters, etc.

\subsection{Microstructural Investigation}

\subsubsection{Microstructure of the CCGTA Welding}

Interfacial microstructures of the CCGTA welded samples are shown in Figure 4. Investigations revealed that secondary phases prominently present as an unmixed zone (UZ) on all Inconel 625 sides (Figure 4b,d,f). The UZ on the Inconel 625 side welded with an ERNiCr3 filler has disappeared, although no aging treatment was performed. A partially melted zone (PMZ) was observed in the 
interface on the AISI 316L side with TIG 316L and twisted fillers (Figure 4c,e). Additionally, equi-axed and columnar dendrites were observed in the weld zone (WZ) microstructure on the AISI 316L sides.
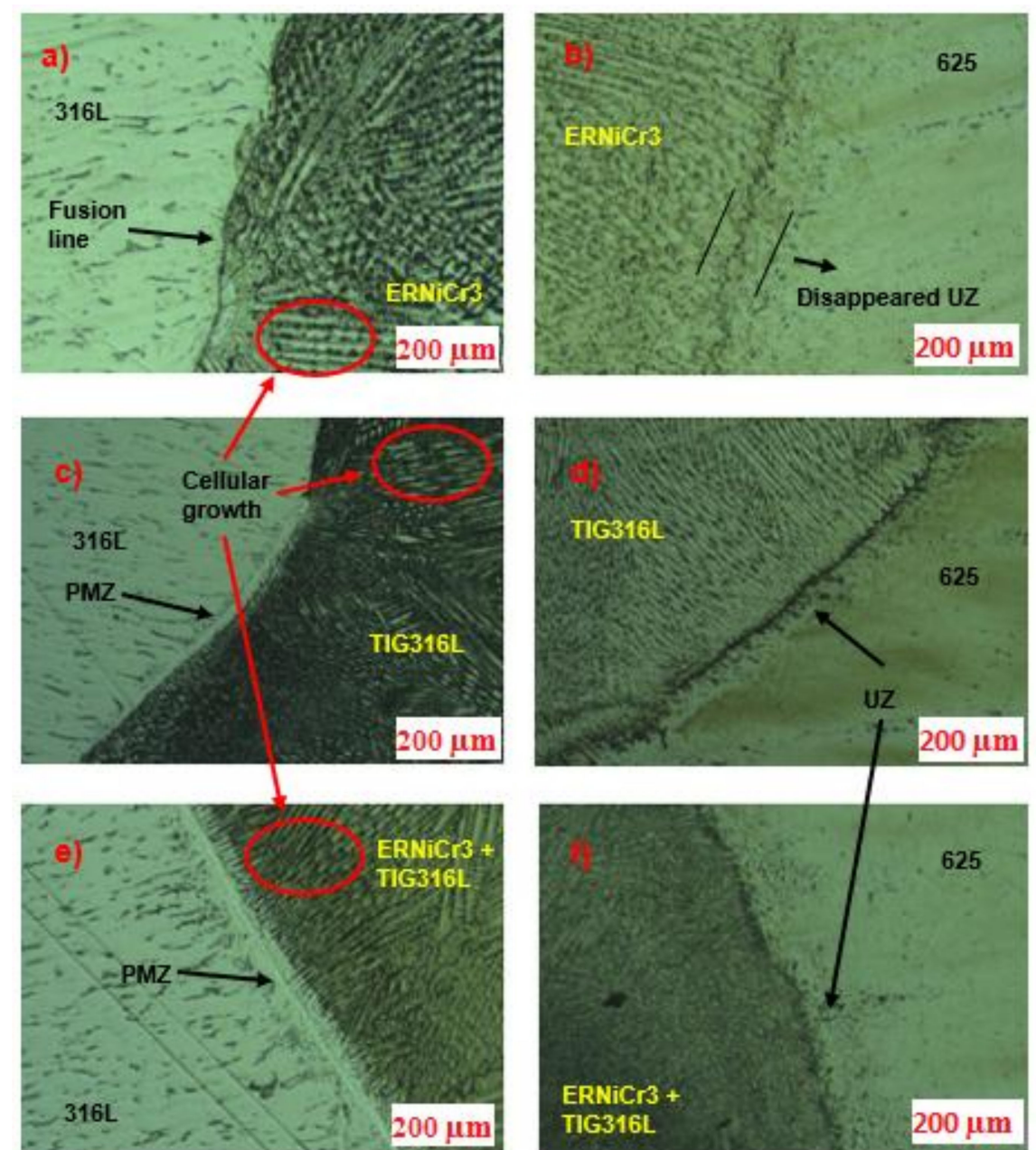

Figure 4. Microstructures of bimetallic joints of Inconel 625 and AISI 316L obtained by CCGTA welding, employing ERNiCr3 (a,b), TIG 316L (c,d), Twisted Fillers (e,f).

\subsubsection{Microstructure of the PCGTA Welding}

Interfacial microstructures of the PCGTA welded samples are shown in Figure 5. Secondary phases of UZ were also obtained in PCGTA welding. Particularly on the Inconel 625 side of 316L welding with twisted fillers (Figure 5d,f), UZ is clearer. On the AISI 316L side, equi-axed and columnar dendrites were observed in WZ. Twisted fillers presented PMZ on the AISI 316L side, and UZ disappeared on the Inconel 625 side. However, minimum grain coarsening was observed in WZ, which indicates improved metallurgical properties. 

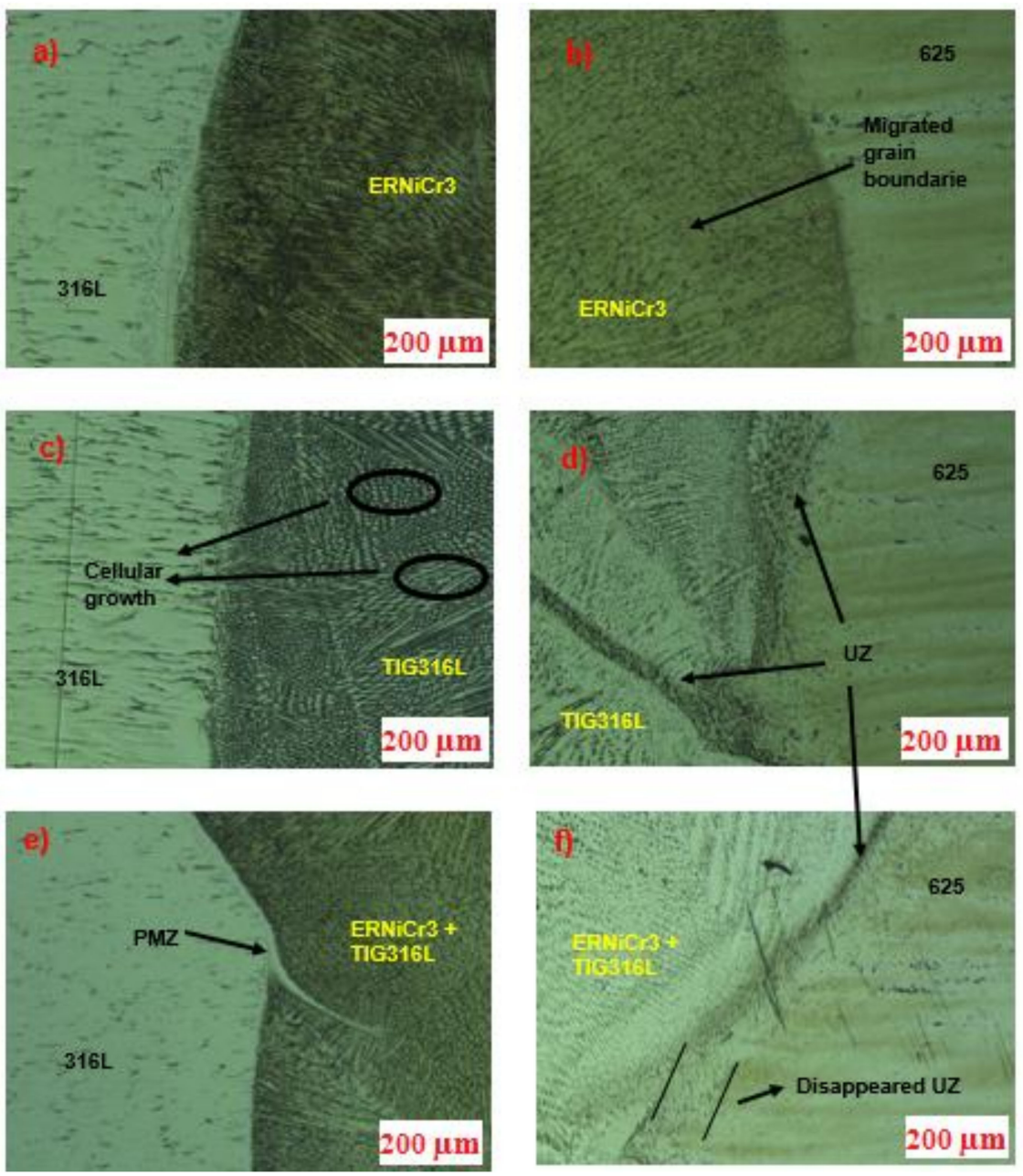

Figure 5. Microstructures of bimetallic joints of Inconel 625 and AISI 316L obtained by PCGTA welding, employing ERNiCr3 (a,b), TIG 316L (c,d), Twisted Fillers (e,f).

\subsubsection{Line Mapping Analysis of the CCGTA Welding}

Line mapping analysis of the CCGTA welding process is represented in Figure 6. Major elemental transfers has been detected as Ni, Fe and $\mathrm{Cr}$. As can be seen in Figure 6a-c, Fe moved from AISI 316L to $\mathrm{WZ}$ or vice versa, and $\mathrm{Ni}$ moved from $\mathrm{WZ}$ to AISI 316L, in all filler types. $\mathrm{Nb}$ and Mo transfers occurred from Inconel 625 to WZ relatedly. Cr migration is meager in all experiments. 


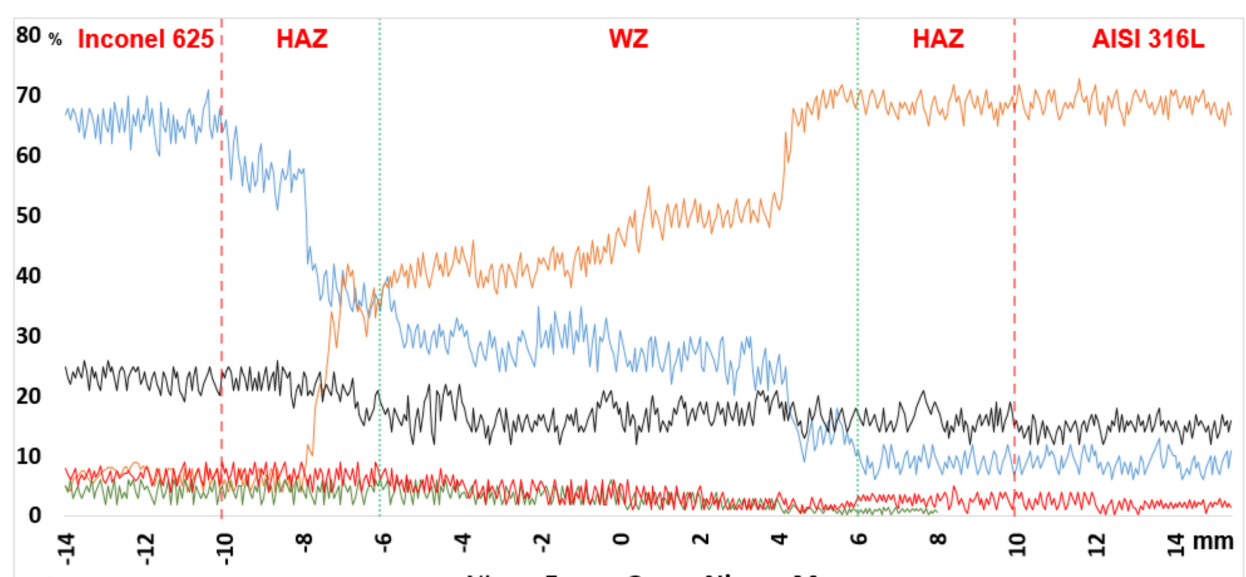

a) $-\mathrm{Ni}-\mathrm{Fe}-\mathrm{Cr}-\mathrm{Nb}-\mathrm{Mo}$
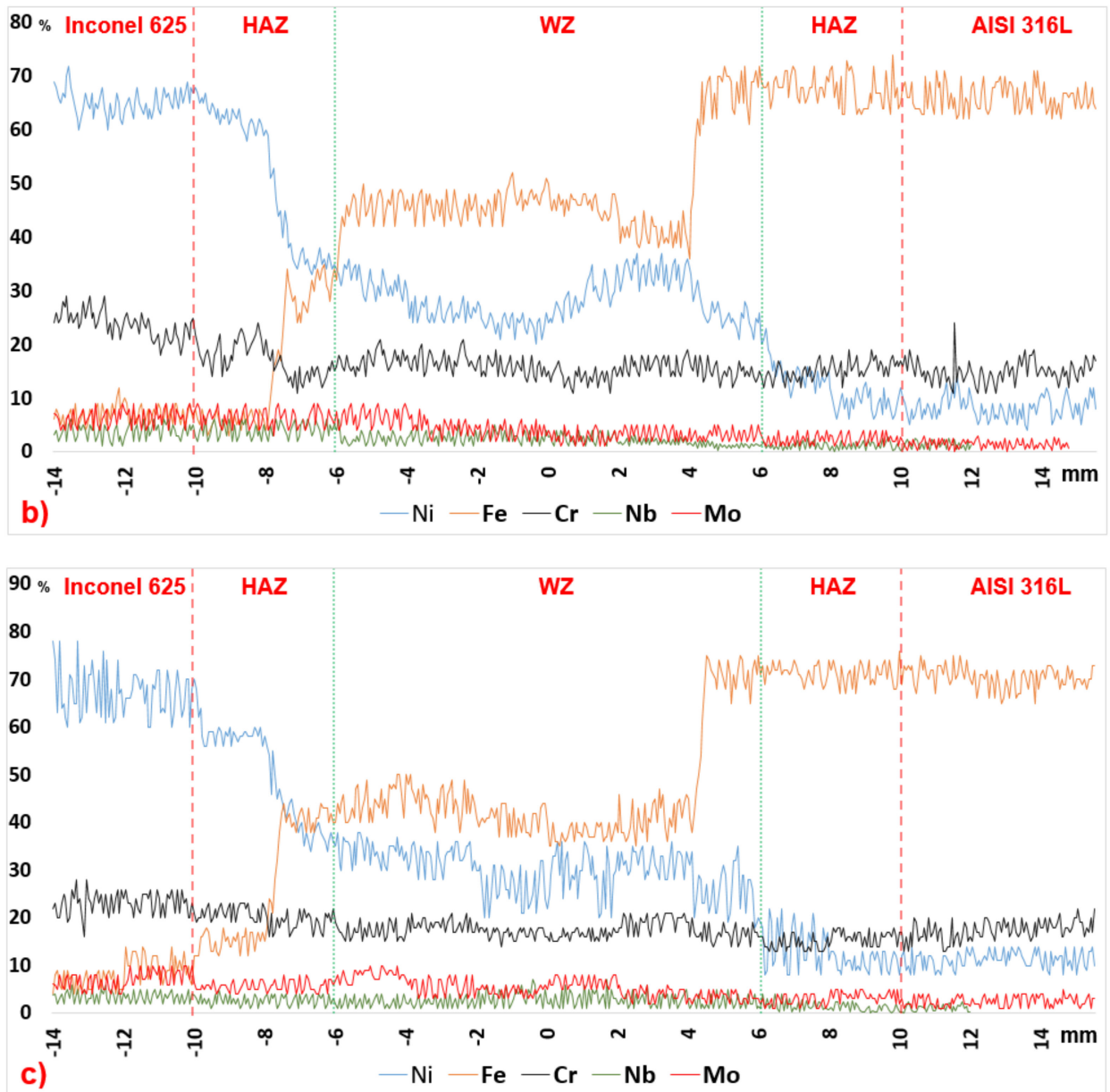

Figure 6. Line mapping analysis of bimetallic joints of Inconel 625 and AISI 316L obtained by CCGTA welding, employing ERNiCr3 (a), TIG 316L (b), Twisted Filler (c).

\subsubsection{Line Mapping Analysis of the PCGTA Welding}

Line mapping analysis of the PCGTA welding process is represented in Figure 7. In all cases, the element Fe migrated from AISI 316L to WZ and vice versa, and the element Ni migrated from WZ to AISI 316L, as shown in Figure 7d,e,f. A meager amount of $\mathrm{Cr}$ migration from both Inconel 625 to $\mathrm{WZ}$ and from AISI 316L to WZ was observed for all fillers. Maximum amount of $\mathrm{Nb}$ migration was observed from Inconel 625 to WZ employing TIG 316L. 

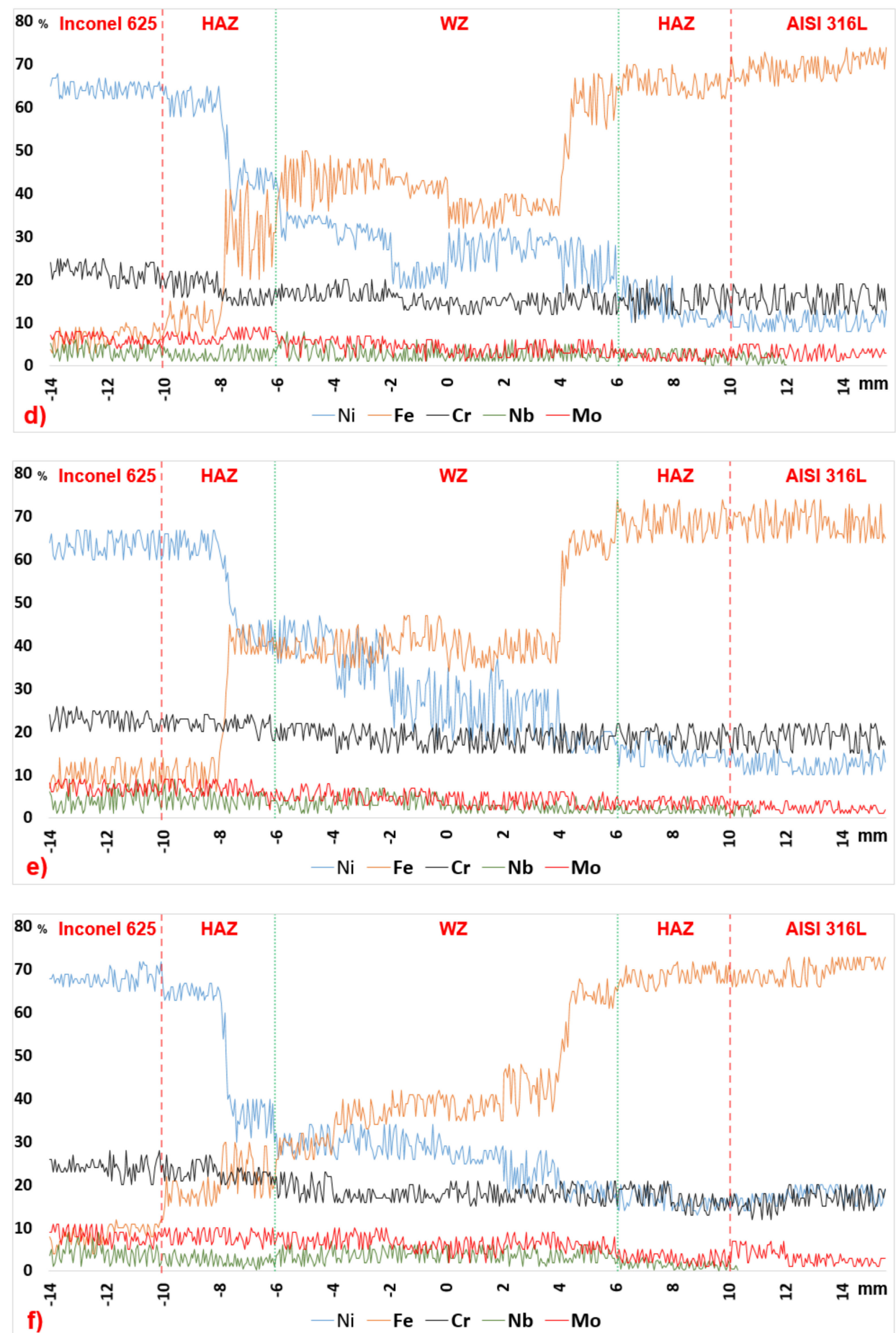

Figure 7. Line mapping analysis of bimetallic joints of Inconel 625 and AISI 316L obtained by PCGTA welding, employing ERNiCr3 (d), TIG 316L (e), Twisted Filler (f).

\subsubsection{SEM/EDAX Analysis of CCGTA Welding}

The presence of tiny secondary phases, which are represented in white in Figure 8, was observed in the SEM/EDAX spot analysis of the weld zones of CCGTA welding. Analysis showed that these secondary phases in the fusion zone consisted of an enriched amount of $\mathrm{Nb}, \mathrm{Cr}, \mathrm{Mo}, \mathrm{Ni}$ and $\mathrm{Nb}$. The pitting points, Spot 4 and Spot 6, contain a restricted element, whereas other shiny white spots contain a great number of elements. Secondary phases were found to be continuous in all weldments. 

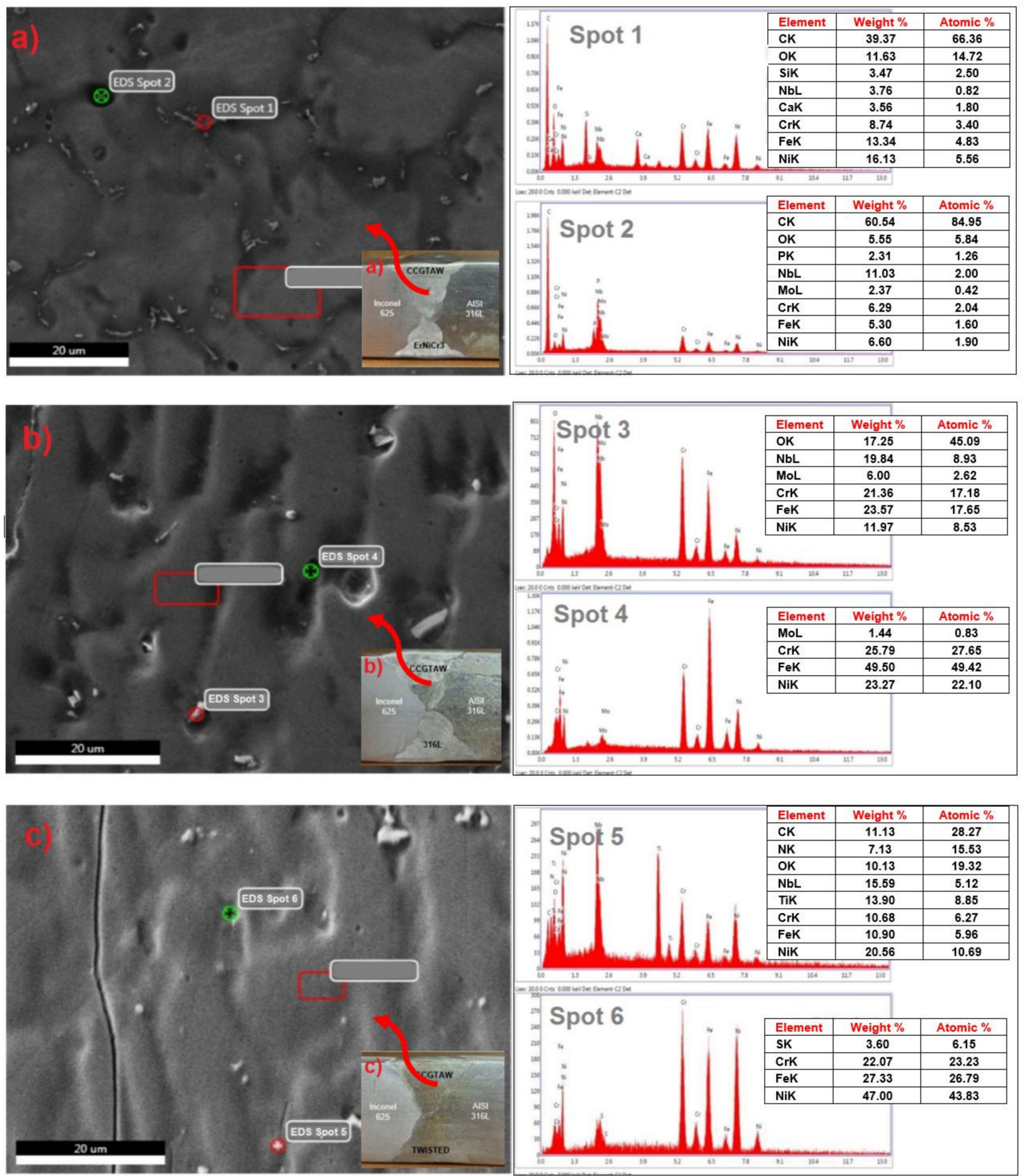

Figure 8. SEM/EDAX point analysis of the dissimilar CCGTA welding of Inconel 625 and AISI 316L, employing ERNiCr-3 (a), TIG 316L (b), Twisted Filler (c).

\subsubsection{SEM/EDAX Analysis of PCGTA Welding}

SEM/EDAX point analysis results of PCGTA welding zones are given in Figure 9. Secondary phases contain an enriched amount of $\mathrm{Al}, \mathrm{Nb}, \mathrm{Ni}, \mathrm{Cr}$ and $\mathrm{Ti}$, and they are found to be continuous. In ERNiCr3 and TIG 316 filler results, only a specific element was determined. The twisted filler created more element movement at WZ. 

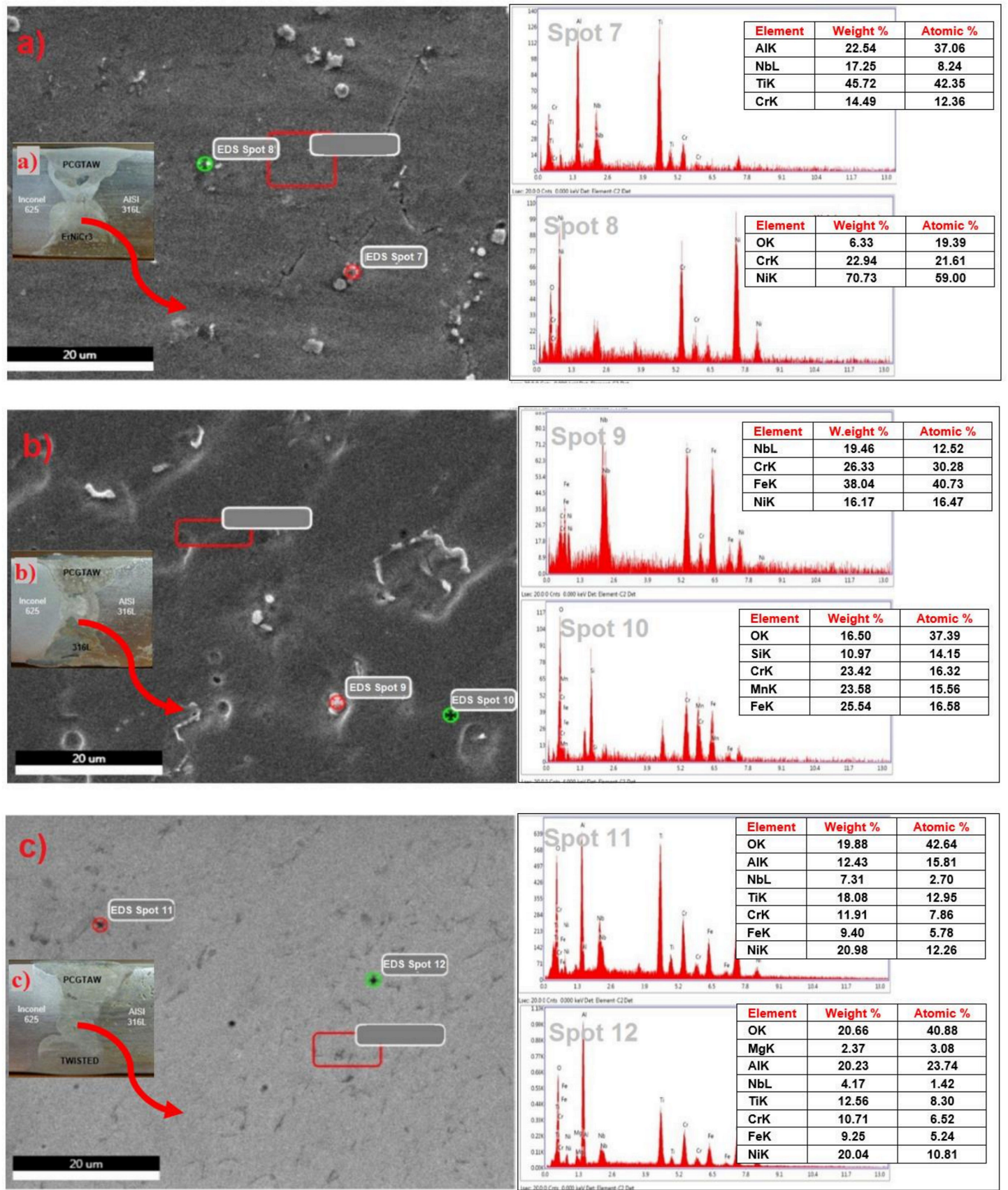

Figure 9. SEM/EDAX point analysis of the dissimilar PCGTA welding of Inconel 625 and AISI 316L, employing ERNiCr-3 (a), TIG 316L (b), Twisted Filler (c).

\subsection{Mechanical Investigation}

\subsubsection{Hardness Tests}

The micro-hardness measurements were made by using Vickers hardness tester. Hardness studies were carried out across the entire width of the weldments vis-à-vis cap, filler and root passes. Results are given in Figure 10. The average weld hardness for CCGTA welding was found minimum in the root pass $265.16 \mathrm{HV}, 245.10 \mathrm{HV}, 250.85 \mathrm{HV}$ employing ERNiCr-3, TIG 316L and twisted fillers respectively. Peak hardness value was measured $(385.30 \mathrm{HV})$ at the cap pass employing ERNiCr-3 filler metal. The average weld hardness for whole weldment was found to be its maximum $(281.72 \mathrm{HV})$ employing ERNiCr-3 filler metal. 

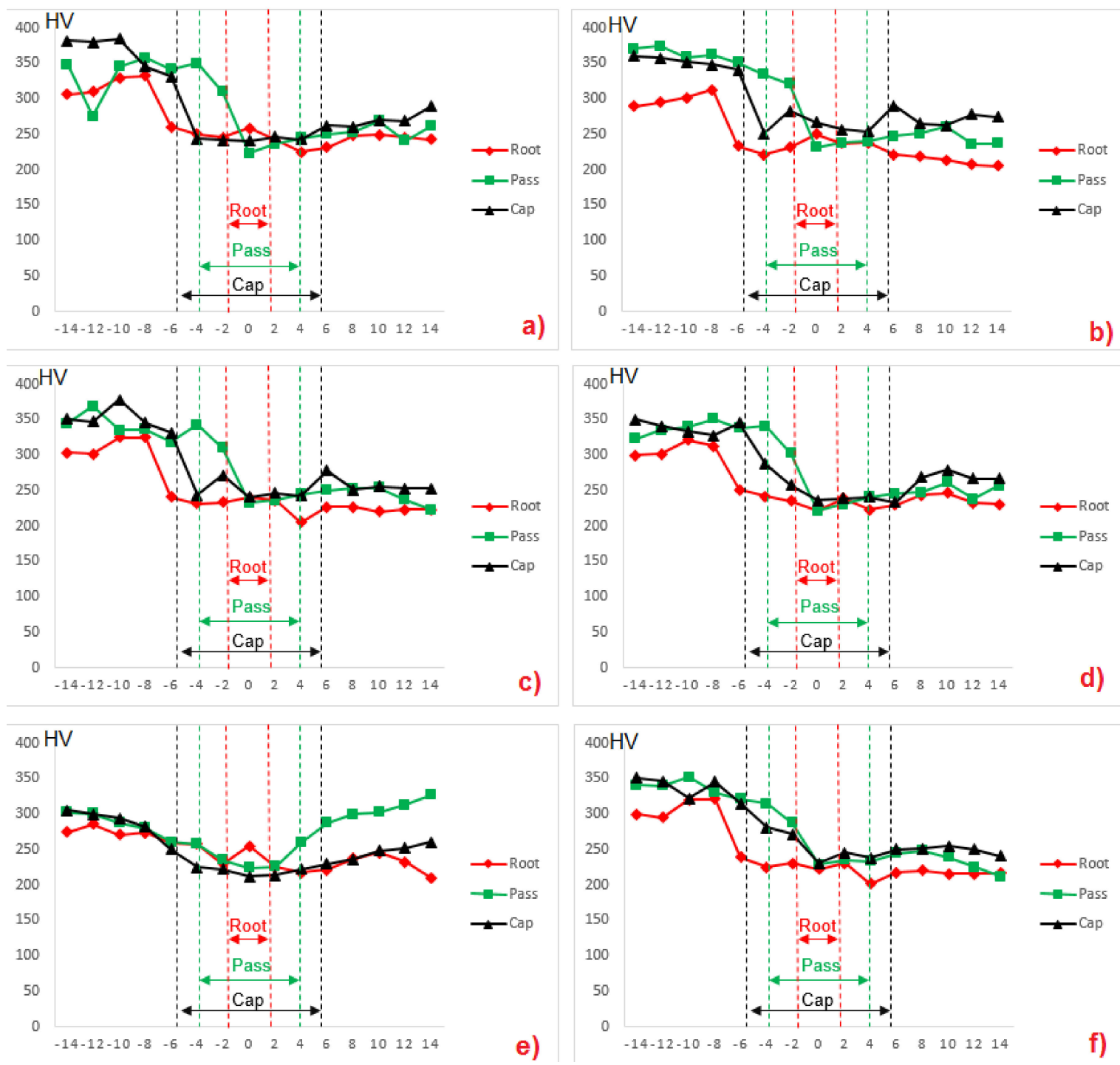

Figure 10. Micro hardness results for CCGTA welding employing ERNiCr-3 (a), TIG 316L (b), Twisted Filler (c), and PCGTA welding employing ERNiCr-3 (d), TIG 316L (e), Twisted Filler (f).

The average weld hardness for PCGTA welding was found minimum in the root pass similar with CCGTAW, with values 255.34 HV, 246.33 HV, 244.78 HV employing ERNiCr-3, TIG 316L and twisted fillers respectively. Peak hardness value was measured $(389.63 \mathrm{HV})$ at the filler pass employing ERNiCr-3 filler metal. The average weld hardness for whole weldment was found maximum (275.08 HV) employing ERNiCr-3 filler metal.

\subsubsection{Tensile Test}

Tensile test was carried out on the dissimilar weldments obtained from the CCGTA and PCGTA welding techniques employing ERNiCr-3, TIG 316L and twisted fillers, and are shown in Figure 11. Results of CCGTA weldments clearly depicted that the fractures occurred at WZ employing ERNiCr-3 and TIG 316L, whereas fracture occurred at parent metal of AISI 316L side employing twisted fillers. Results of PCGTA weldments have shown that the fracture occurred at WZ employing ERNiCr-3, whereas fractures occurred at parent metal of AISI 316L side employing TIG 316L and twisted fillers. 


\section{CCGTAW}

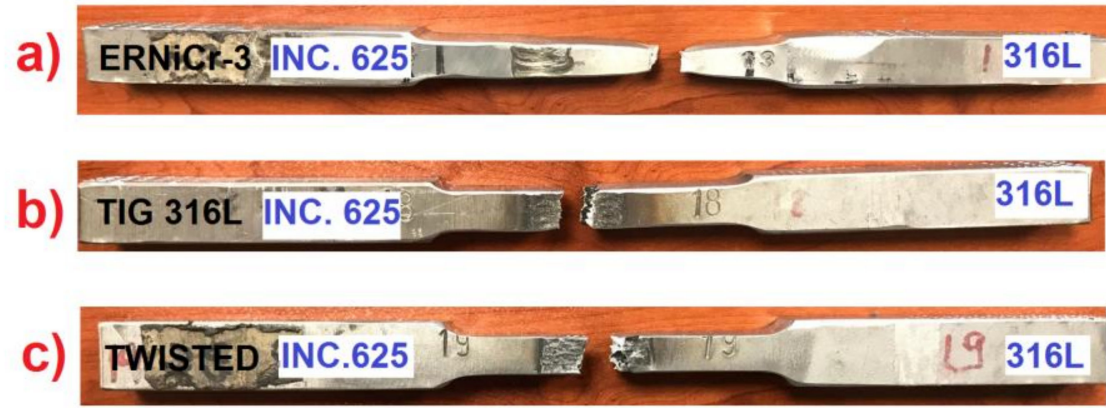

\section{PCGTAW}

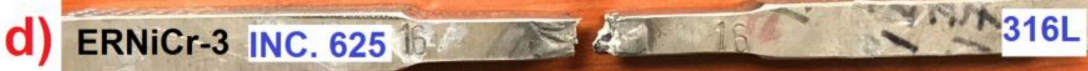

e) TIG 316L INC. 625 I PBS $316 \mathrm{~L}$

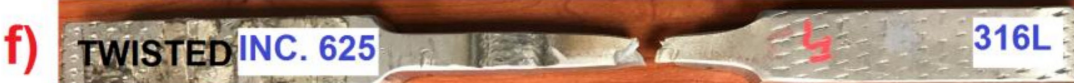

Figure 11. Tensile test results CCGTAW employing ERNiCr-3 (a), TIG 316L (b), Twisted Filler (c), and PCGTA welding employing ERNiCr-3 (d), TIG 316L (e), Twisted Filler (f).

The average tensile test properties of the CCGTA and PCGTA weldments are represented in Table 3. As it seen from the results, ductility measured in terms of percentage elongation at the break load 34\%, 32\% and 36\% (CCGTAW emp. ERNiCr-3, PCGTAW emp. TIG 316L, PCGTAW emp. twisted, respectively) which fractures occurred at parent metal of AISI 316L.

Table 3. Tensile Test Results of CCGTAW and PCGTAW

\begin{tabular}{ccccc}
\hline Weldment & $\begin{array}{c}\text { Yield Strength } \\
\mathbf{( M P a )}\end{array}$ & $\begin{array}{c}\text { Tensile Strength } \\
\mathbf{( M P a )}\end{array}$ & Elongation (\%) & Fracture Zone \\
\hline CCGTAW emp. ERNiCr-3 & 442 & 674 & 34 & AISI 316L \\
CCGTAW emp. TIG 316L & 389 & 529 & 13 & WZ \\
CCGTAW emp. Twisted & 437 & 567 & 19 & WZ \\
PCGTAW emp. ERNiCr-3 & 401 & 532 & 17 & WZ \\
PCGTAW emp. TIG 316L & 446 & 661 & 32 & AISI 316L \\
PCGTAW emp. Twisted & 451 & 687 & 36 & AISI 316L \\
\hline
\end{tabular}

\section{Discussion}

Non-Destructive Testing (NDT) analysis and macro-photograph observations show that all weldments were free from gap, lack of penetration, spatter, defects, etc. This indicated that all techniques and filler metals were proper for the dissimilar welding of Inconel 625 and AISI 316L.

The interfacial and weld zone microstructures of CCGTA and PCGTA welding are given in Figures 4 and 5, respectively. Employing TIG 316L and twisted fillers, clear PMZs were observed in the HAZ of CCGTA welding (Figure 4c,e). PMZ generally formed right next to the exterior of the fusion zone, where the material is over-heated by the eutectic temperature [31]. PMZ could cause cracking, and this is an undesirable result. Figure $8 \mathrm{c}$ depicts an obvious crack. It is clear that widest PMZ's are concretized cracking. Figures 4 and 5 show CCGTA and PCGTA welding microstructures; widest PMZ's were determined in CCGTA welding employing twisted fillers (Figure 4e,f). Employing twisted 
filler by using CCGTA welding might cause unknown chemical composition at WZ, which leads to PMZ, hence cracking. However, UZs were obviously determined at the HAZ of Inconel 625 with TIG 316L and twisted fillers (Figure 4d,f). In the dissimilar welding process, UZ formation is an expectation when the melting range of base and filler metals is largely varying. In this connection, the heat input was not able to provide a proper welding pool, leading to the formation of an unmixed zone [8,32]. Researchers observed that the UZ area is greater on the nickel-based Inconel 625 side compared with that on the AISI 316L side. Dev et al. [8] exhibited similar results in their study, and they attributed them to the melting-solidification rate of the nickel element. UZs were also confirmed in the HAZ on the PCGTA welding Inconel 625 side, as shown in Figure 5d,e. It is confirmed that the current type could not prevent the formation of UZ. Multi-pass welding might cause a multi directional grain growth, however, PCGTA welding could control grain growth at WZ [23]. In PCGTA welding, peak and back currents provide a fluctuation of temperature in the weld pool, which effects the grain configuration during solidification. It can be seen in Figure 5 that PCGTA welding controls the grain growth, excepting the TIG 316L welded specimen. Naffakh et al. [22] subjected dissimilar weldments of Inconel 657 and AISI 310 to heat treatment after welding. UZs disappeared as a consequence of the heat treatment. CCGTA welding with ERNiCr-3, shown in Figure 4a, and PCGTA welding with the twisted filler, shown in Figure 5f, indicate that UZs also disappeared without any heat treatment. Researchers tend to agree that a homogeneous cooling rate might occur in these regions. In PCGTA welding with ERNiCr-3, shown in Figure 5b, Migrated Grain Boundaries (MGBs) were clearly observed at WZ. According to DuPont et al. [15], an Ni-rich filler ensures a fully austenitic phase in WZ in addition to multi-pass welding, which would likely cause MGBs.

Line mapping analysis demonstrated a migration of elements on both sides. In CCGTA welding, Fe movement from AISI 316L to WZ or vice versa, and Ni movement from WZ to AISI 316L, was observed. Due to similar chemical compositions (Table 1), Ni and Cr movements from Inconel 625 to WZ were minimal, as shown in Figure 6. A meager amount of $\mathrm{Cr}$ migration from AISI 316 to WZ for all fillers ERNiCr3 and TIG 316L fillers has been observed. Due to the difference in the chemical composition of the metals, Ni migrated from Inconel 625 to WZ (Figure 6d). In PCGTA welding, a miserable Cr movement was observed with ERNiCr-3 and twisted fillers, as shown in Figure 7d,f. Employing twisted fillers reveals the dramatically edged migrations of $\mathrm{Fe}$ and Ni elements, which tend to mix the two metals.

SEM/EDAX analysis indicated that the formation of $\mathrm{Nb}-, \mathrm{Ti}-, \mathrm{Cr}-, \mathrm{Mo}-, \mathrm{Mn}-$ and Ni-rich phases occurred in the WZs. Similar precipitations were observed at the HAZ of Inconel 625 and HAZ of AISI 316L for all specimens. It is well-known that deleterious secondary phases may reduce the corrosion resistance of weldment [24]. The formation of $\mathrm{Nb}$-rich secondary phases was observed on the GTA welds with ERNiCr-3 because of its $\mathrm{Nb}$ content. As expected, the formation of $\mathrm{Nb}$-rich phases in CCGTA welding with an ERNiCr-3 filler can clearly be seen in Figure 8a. However, secondary phase formation was slightly reduced with PCGTA welding, as shown in Figure 9a. Kumar et al. [25] also found similar microstructural results in their study. Nevertheless, $\mathrm{Nb}, \mathrm{Ti}, \mathrm{Ni}$ and $\mathrm{Cr}$ precipitates were located, which also reduces the corrosion resistance [10]. The TIG 316L filler material does not contain $\mathrm{Nb}$ in the chemical composition, although an $\mathrm{Nb}$-rich formation was confirmed. $\mathrm{Nb}$ migrated from Inconel 625 to WZ. This caused the formation of a Laves phase, as can be seen in Spot 3. In Figure 8c, an enriched amount of $\mathrm{Nb}, \mathrm{Ti}, \mathrm{Cr}$ and Ni precipitates occurred in CCGTA welding with twisted fillers. $\mathrm{Ti}$ and Ni elements at a high temperature using the welding process are prone to form TiN [33]. The TiN phase was inert when the Laves phases occurred. $\mathrm{Nb}-, \mathrm{Cr}-, \mathrm{Ni}-$ and $\mathrm{Mn}$-rich precipitation is illustrated in Figure 9b. The analysis of PCGTA welding with twisted fillers is demonstrated in Figure 9c. According to the figure, the absence of white secondary phases was observed. However, differently viewed, infrequent secondary phases represented by black dot shapes also occurred. These phases contain a rich amount of $\mathrm{Al}, \mathrm{Ti}, \mathrm{Cr}$ and $\mathrm{Ni}$. This is the lowest density formation compared with the other experiments. The main welding parameter was current type. In the experiments, pulse current leads to control solidification phases. Therefore, PCGTA welding ensures the minimization of secondary 
phase formation. These results support the study of Kumar et al. [25]. In sum, the OM results also support the SEM results that PCGTA welding with twisted fillers has the best metallurgical properties.

When welded metals cool slowly, they cause the extension of micro-segregation. To minimize micro-segregation heat input should be reduced. In other words, minimum heat input would increase cooling rate, and this helps to reduce segregation of $\mathrm{Nb}$ and Laves phase [26]. CCGTA and PCGTA welding processes have nearly the same heat input with stationary welding parameters as base metal filler, current etc. Researchers observed Laves Phases PCGTA welded specimens. Authors suppose that high current range could cause high heat input and so form Laves phases.

It is evident from the hardness tests that maximum WZ hardness magnitudes were detected at ERNiCr-3 welded specimens for both CCGTA and PCGTA welding (Figure 10). This could be formation of secondary phases. PCGTA welding hardness results are lower that CCGTA welding results. It is clear from the micro hardness results that PCGTA welding reduces the formation of secondary phases, which improves the properties of weldments. Fracture occurred at WZ in three tests. The obvious crack, which can be seen at SEM analysis, was cause to reduced weld tensile strength. The researchers observed micro-cracks in the $\mathrm{WZ}$ which was due to the segregation of $\mathrm{Nb}$. These micro cracks were caused due to fractures at WZ during tensile test of PCGTA welding employing ERNiCr-3. This result is conflict with the study of Kumar et al. [25], which could be peak current differences between the studies. Authors commented that peak-base current for ERNiCr-3 was selected high. Tensile test results show that sample PCGTA welding employing twisted fillers exhibits the highest tensile strength and elongation.

\section{Conclusions}

This study investigates the microstructural properties of the dissimilar metal welding of a nickel-based super alloy, Inconel 625, and an austenitic stainless steel, AISI 316L, obtained by CCGTA and PCGTA welding with ERNiCr-3, TIG 316L and twisted (ERNiCr-3 and TIG 316L) fillers. The results of the study can be summarized as follows:

- Successful weldments obtained for all specimens in terms of macrostructure, without any lack of penetration, crack, spatter, etc.

- Microstructural investigations illustrated that in CCGTA welding with TIG 316L and twisted fillers, PMZs were obtained, which may cause cracking. TIG 316L filler metal weldments showed grain coarsening and twisted fillers could produce a laxer chemical composition with CCGTA welding process. However, CCGTA welding with ERNiCr-3 demonstrated almost regular boundaries on both sides. PCGTA welding with twisted fillers showed PMZ on the AISI 316L side and caused UZ to disappear on the Inconel 625 side. PCGTA welding reduced PMZ and UZ employing twisted fillers and minor grain coarsening.

- WZ microstructural analysis exhibited the existence of multi-directional grain growth in all specimens on the AISI 316L side. Grain growth was less on the Inconel 625 side and almost disappeared on the Inconel 625 side in PCGTA welding with twisted fillers.

- It was observed that the formation of $\mathrm{Ni}-, \mathrm{Ti}^{-}, \mathrm{Nb}-, \mathrm{Mo}-, \mathrm{Mn}$ - and $\mathrm{Cr}$-rich secondary precipitates appeared in all specimens. However, in PCGTA welding with twisted fillers, a meager amount of precipitates occurred. Moreover, these are particular precipitates that are represented by black dots in images, whereas others are tiny white secondary phases.

- Hardness and tensile test results show that PCGTA welding improve mechanical properties. Twisted fillers exhibit the best mechanical properties for bimetallic joint for Inconel 625 and AISI 316L.

- According to the study results, for the dissimilar metal welding of Inconel 625 and AISI 316L, the best process is PCGTA with twisted fillers (ERNiCr-3 and TIG 316L).

The results of the study will be very useful for the Original Equipment Manufacturers (OEM) in producing equipment with bimetallic joints. 
Author Contributions: Conceptualization, F.D. and M.K.K.; methodology, F.D., M.K.K. and U.E.; formal analysis, F.D.; investigation, F.D. and M.K.K.; resources, F.D.; data curation, F.D., M.K.K. and U.E.; writing-original draft preparation, F.D.; writing-review and editing, F.D.; visualization, M.K.K. and U.E.; supervision, M.K.K.; project administration, M.K.K. and U.E.; funding acquisition, F.D.

Funding: This work was supported by Sisecam Chemicals Group Soda Sanayii A. S. Kromsan Chromium Chemicals Plant.

Acknowledgments: The authors would like to thank Sisecam Chemicals Group Soda Sanayii A. S. in Mersin, Turkey for their support of this study. Special appreciation is also expressed to Kromsan Chromium Chemical Plant mechanical maintenance personnel who helped to prepare experiments.

Conflicts of Interest: The authors declare no conflicts of interest.

\section{References}

1. Moosavy, H.N.; Aboutalebi, M.R.; Seyedein, S.H.; Mapelli, C. A Solidification Model for Prediction of Castability in the Precipitation-strengthened Nickel-based Superalloy. J. Mater. Process. Technol. 2013, 213, 1875-1884. [CrossRef]

2. Korrapati, P.K.; Avasarala, V.K.; Bhushan, M.; Ramkumar, K.D.; Arivazhagan, N. Narayanan, S. Assessment of Mechanical Properties of PCGTA Weldments of Inconel 625. Procedia Eng. 2014, 75, 9-13. [CrossRef]

3. Shankar, V.; Sankara, K.B.; Mannan, S.L. Microstructural and Mechanical Properties of Inconel 625 Superalloy. J. Nucl. Mater. 2001, 288, 222-232. [CrossRef]

4. Ramkumar, K.D.; Mithilesh, P.; Varun, D.; Reddy, A.R.G.; Arivazhagan, N.; Narayanan, S.; Kumar, K.G. Characterization of Microstructure and Mechanical Properties of Inconel 625 and AISI 304 Dissimilar Weldments. J. Int. Ste. Inst. Jap. 2014, 54, 900-908. [CrossRef]

5. American Welding Society. Available online: https://app.aws.org/wj/2002/06/feature2/ (accessed on 23 September 2018).

6. Dreshfield, R.L.; Moore, T.J.; Bartolotta, P.A. Post-Test Examination of a Pool Boiler Receiver. DOE/NASA/33408-6; U.S Department of Energy Conservation and Renewable Energy Office of Solar Heat Technologies: Washington, WA, USA, 1992; pp. 1-4.

7. Mitilesh, P.; Varun, D.; Reddy, A.R.G.; Ramkumar, K.D.; Arivazhagan, N.; Narayanan, S. Investigations on Dissimilar Weldments of Inconel 625 and AISI 304. Procedia Eng. 2014, 75, 66-70. [CrossRef]

8. Dev, S.; Ramkumar, K.D.; Arivazhagan, N.; Rajendran, R. Investigations on the Microstructure and Mechanical Properties of Dissimilar Welds of Inconel 718 and Sulphur Rich Martensitic Stainless Steel AISI 416. J. Manuf. Process. 2018, 32, 685-689. [CrossRef]

9. Mortezaie, A.; Shamanian, M. An Assessment of Microstructure, Mechanical Properties and Corrosion Resistance of Dissimilar Welds between Inconel 718 and 310 S Austenitic Stainless Steel. Int. J. Press. Vessel. Pip. 2014, 116, 37-46. [CrossRef]

10. Ramkumar, T.; Selvakumar, M.; Narayanasamy, P.; Begam, A.A.; Mathavan, P.; Raj, A.A. Studies on the Structural Property, Mechanical Relationships and Corrosion Behaviour of Inconel 718 and SS 316L Dissimilar Joints by TIG welding without Using Activated Flux. J. Manuf. Process. 2017, 30, 290-298. [CrossRef]

11. Ahmad, H.W.; Hwang, J.H.; Lee, J.H.; Bae, D.H. An Assessment of the Mechanical Properties and Microstructural Analysis of Dissimilar Material Welded Joint between Alloy 617 and 12Cr Steel. Metals 2016, 6, 242. [CrossRef]

12. Kim, J.S.; Park, Y.I.; Lee, H.W. Effects of Heat Input on the Pitting Resistance of Inconel 625 Welds by Overlay Welding. Met. Mater. Int. 2015, 21, 350-355. [CrossRef]

13. Knapp, S. Mechanical Properties of an Inconel Dissimilar Metal Weld. Master's Thesis, University of Ottowa, Ottawa, ON, Canada, 2013.

14. Kulekci, M.K.; Esme, U.; Kahraman, F.; Ocalir, S. An examination of the mechanical properties of dissimilar steel welds. Mater. Test. 2016, 58, 362-370. [CrossRef]

15. Badiger, R.I.; Narendranath, S.; Srinath, M.S. Microstructure and Mechanical Properties of Inconel-625 Welded Joint Developed Through Microwave Hybrid Heating. J. Eng. Manuf. 2017. [CrossRef]

16. DuPont, J.N.; Lippold, J.C.; Kiser, S.D. Welding Metallugy and Weldability of Nickel-Base Alloys; John Wiley \& Sons, Inc.: Hoboken, NJ, USA, 2009; pp. 82-100.

17. Manikandan, S.G.K.; Sivakumar, D.; Rao, K.P.; Kamaraj, M. Microstructural Characterization of Liquid Nitrogen Cooled Alloy 718 fusion zone. J. Mater. Process. Technol. 2014, 214, 3141-3149. [CrossRef] 
18. Ramkumar, K.D.; Kumar, P.S.G.; Krishna, V.R.; Chandrasekhar, A.; Dev, S.; Abraham, W.S.; Prabhakaran, S.; Kalainathan, S.; Sridhar, R. Influence of Laser Peening on the Tensile Strength and Impact Toughness of Dissimilar Welds of Inconel 625 and UNSS32205. Mater. Sci. Eng. A 2016, 676, 88-99. [CrossRef]

19. Olden, V.; Kvaale, P.E.; Simensen, P.A.; Aaldstedt, S.; Solberg, J.K. The Effect of PWHT on the Material Properties and Microstructure in Inconel 625 and Inconel 725 Buttered Joints. In Proceedings of the 22nd International Conference on Offshore Mechanics and Artic Engineering, Cancun, Mexico, 8-13 June 2003.

20. Soares, B.A.; Schvartzman, M.M.A.M.; Campos, W.R.C. Characterization of Dissimilar Metal Welding-Austenitic Stainless Steel with Filler Metal of the Nickel Alloy. In Proceedings of the International Nuclear Atlantic Conference, Sao Paolo, Brazil, 30 September-5 October 2007.

21. Prabu, S.S.; Ramkumar, K.D.; Arivazhagan, N. Microstructural Evolution and Precipitation Behavior in Heat Affected Zone of Inconel 625 and AISI 904L Dissimilar Welds. Mater. Sci. Eng. 2017, 263, 062073. [CrossRef]

22. Naffakh, N.; Shamanian, M.; Ashrafizadeh, F. Microstructural evolutions in dissimilar welds between AISI 310 austenitic stainless steel and Inconel 657. J. Mater. Sci. 2010, 45, 2564-2573. [CrossRef]

23. Ramkumar, K.D.; Patel, S.D.; Praveen, S.S.; Choudhury, D.J.; Prabaharan, P.; Arivazhagan, N.; Xavior, M.A. Influence of Filler Metals and Welding Techniques the Structure-Property Relationships of Inconel 718 and AISI 316L Dissimilar Weldments. Mater. Des. 2014, 62, 175-188. [CrossRef]

24. Hejripour, F.; Aidun, D.K. Consumable Selection for Arc Welding between Stainless Steel 410 and Inconel 718. J. Mater. Process. Technol. 2017, 245, 287-299. [CrossRef]

25. Kumar, K.G.; Ramkumar, K.D.; Arivazhagan, N. Characterization of Metallurgical and Mechanical Properties of the multi-pass welding of Inconel 625 and AISI 316L. J. Mech. Sci. Tech. 2015, 29, 1039-1047. [CrossRef]

26. Kourdani, A.; Haghighi, R.D. Evaluating the Properties of Dissimilar Metal Welding Between Inconel 625 and 316L Stainless Steel by Applying Different Welding Methods and Consumables. Metall. Mater. Trans. A 2018, 49A, 1231-1243. [CrossRef]

27. Xie, M.X.; Shang, X.T.; Zhang, L.J.; Bai, Q.L.; Xu, T.T. Interface Characteristic of Explosive-Welded and Hot-Rolled TA1/X65 Bimetallic Plate. Metals 2018, 8, 1-14. [CrossRef]

28. Topolski, T.; Szulc, Z.; Garbacz, H. Microstructure and Properties of the Ti6Al4V/Inconel 625 Bimetal Obtained by Explosive Joining. J. Mat. Eng. Perf 2016. [CrossRef]

29. Mohommed, G.H.; Ishak, M.; Ahmad, S.N.A.S.; Abdulhadi, H.A. Fiber Laser Welding of Dissimilar 2205/304 Stainless Steel Plates. Metals 2017, 7, 1-19. [CrossRef]

30. Shakil, M.; Ahmad, M.; Tariq, N.H.; Hasan, B.A.; Akhter, J.I.; Ahmed, E.; Mehmood, M.; Choudhry, M.A.; Iqbal, M. Microstructure and hardness studies of electron beam welded Inconel 625 and stainless steel 304L. Vacuum 2014, 110, 121-126. [CrossRef]

31. Kou, S. Welding Metallurgy, 2nd ed.; John Wiley \& Sons, Inc.: New York, NY, USA, $2003 ;$ p. 151. ISBN 978-0-471-43491-7.

32. Ramkumar, K.D.; Abraham, W.S.; Viyash, V.; Arivazhagan, N.; Rabel, A.M. Investigations on the Microstructure, Tensile Strength and High Temperature Corrosion Behaviour of Inconel 625 and Inconel 718 Dissimilar Joints. J. Manuf. Process. 2017, 25, 306-322. [CrossRef]

33. Ramkumar, K.D.; Sai, R.J.; Reddy, V.S.; Gundla, S.; Mohan, T.H.; Saxena, V.; Arivazhagan, N. Effect of Filler Wires and Direct Ageing on the Microstructure and Mechanical Properties in the Multi-Pass Welding of Inconel 718. J. Manuf. Process. 2015, 18, 23-45. [CrossRef]

(c) 2018 by the authors. Licensee MDPI, Basel, Switzerland. This article is an open access article distributed under the terms and conditions of the Creative Commons Attribution (CC BY) license (http://creativecommons.org/licenses/by/4.0/). 